S. Afr. J. Agric. Ext.

Vol. 45, No. 1, 2017: $102-117$

Muzawazi, Terblanché

DOI: http://dx.doi.org/10.17159/2413-3221/2017/v45n1a440

\& Madakadze.

\title{
COMMUNITY GARDENS AS A STRATEGY FOR COPING WITH CLIMATE SHOCKS IN BIKITA DISTRICT, MASVINGO, ZIMBABWE.
}

\author{
Muzawazi, H. D. ${ }^{31}$, Terblanché, S. E. ${ }^{32} \&$ Madakadze, C. ${ }^{33}$
}

Corresponding author: H. D. Muzawazi, Email: muzawazid@gmail.com

\begin{abstract}
Drought is the most important climate shock affecting rural farmers this century. In a bid to reduce the effects of climate shocks, coping strategies are being investigated. Community gardens is one such strategy. The purpose of the study was to objectively look at the dynamics involved in community gardens, that is, the significance the gardens have on poverty, food security and income of rural farmers. The study was carried out in Bikita District, Masvingo Province, Zimbabwe. Rural farmers in this area have been hit hard by drought and the effect climate change has had on agricultural production. The main findings of the study showed that community garden participants are mainly women. Many farmers expressed ignorance on the existence and risks associated with climate shocks but agreed that temperatures have increased and rainfall has decreased in the past decade. Several farmers indicated that they do not acquire income from sale of their crops and vegetables, as most are used for household consumption. However, those getting an income use it for basic necessities, children's education and maintaining their farm business. Although there were some constraints, water insufficiency being the largest, community gardens provided many benefits, including social, economic and environmental benefits.
\end{abstract}

Keywords: Community gardens, climate shocks, food security, adaptation, vulnerability, drought, extension services

\section{INTRODUCTION}

In Zimbabwe, rain fed agriculture is a major source of livelihood for most small-holder farmers located in semi-arid regions of the country (Kahinda, Rockstrom, Taigbenu, \& Dimes, 2007). Despite great strides made in improving agricultural productivity in many developing countries, many households in south-east Zimbabwe still face poverty, hunger, food insecurity and malnutrition in those areas where rain fed agriculture is the main source of livelihoods and food. This situation has been exacerbated by the fact that rain fed agriculture is generally overlooked by development investors, researchers and policy makers. However, case studies from Africa and elsewhere demonstrate the potential of rain fed agriculture in achieving food security, improving livelihoods and most importantly addressing issues of equity and poverty reduction in dry land areas - the hot spots of poverty (Wani, Rockstrom, \& Oweis, 2009).

The increased frequencies of extreme weather conditions in the Masvingo Province, particularly in Bikita, are depressing yields and damaging crops especially at the key growth stages. Recurrent and protracted heat waves are causing excessive wilting of crops in the

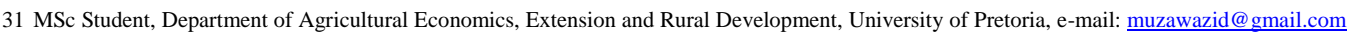

32 Senior Lecturer, Department of Agricultural Economics, Extension and Rural Development, University of Pretoria, Tel. +27 12 420 4958, e-mail: fanie.terblanche@up.ac.za

33 Senior Lecturer, Department of Plant Production and Soil Science, University of Pretoria, Pretoria 0002, Tel. +27 12420 3667, e-mail: casper.madakadze@ up.ac.za

Extract from a dissertation submitted to the University of Pretoria as partial fulfilment for the degree MSc Agricultural Extension.
} 
S. Afr. J. Agric. Ext.

Vol. 45, No. 1, 2017: $102-117$

DOI: http://dx.doi.org/10.17159/2413-3221/2017/v45n1a440
Muzawazi, Terblanché

$\&$ Madakadze.

(Copyright)

fields which has increased the levels of food insecurity in the district, Mutekwa (2009). These findings agree with Slater, Peskett, Ludi \& Brown (2007), who also highlighted that climate change is reversing and slowing down the poverty reducing capacity of agriculture which is simultaneously eroding the source of income and livelihood for the rural poor.

It is against this background that the effects of climate shocks have been felt by the poorer communities such as Bikita, where the majority, if not all of the people, depend on agriculture for their livelihoods. It has been observed that Zimbabwe in general, and particularly Bikita, have witnessed marked transformations in the climatic conditions which are critical for sustainable agricultural activities.

Crop production in Bikita District is highly oriented towards rain fed maize production. A key constraint to livestock production in the communal areas of Bikita is that overgrazing in the wet season does not allow sufficient fodder to be carried over to the dry season resulting in a shortage of fodder during this period. The situation is aggravated by frequent droughts and declining safety net resources of poor farmers in the dryland areas (Unganai \& Murwira, 2010). The risk and uncertainty associated with semi-arid regions is the occurrence of drought and the frequency of crop failure. This means that farmers adopt risk-averse strategies to surpass the dry season (Scoones, 1998). Such strategies, placed in the context of high livestock and human populations may encourage heavy dependence on the environment. Rural communities in Bikita District depend on a wide range of natural products to supplement their livelihoods, most of them derived from the commons.

Water scarcity is one of the greatest limitations to crop productivity in the Southeast part of Zimbabwe which includes Bikita District (Unganai \& Murwira, 2010). Therefore, even modest improvements in crop resistance to drought, infield soil moisture management and in water use efficiency will have significant productivity and economic impacts. As climate change takes root, the water balance of the district is becoming more precarious making household food-insecurity worse. Due to the unreliability of rain fed agricultural, people in Bikita have resorted to alternative livelihood methods such as firewood trading, brick making and community gardening.

After realizing that community gardens were contributing much to the economy and social lives of the past, Non-Governmental Organizations adopted the idea of these community gardens in 1945 to reduce vulnerability of the rural people to poverty. The idea was adopted to reduce the effects of climate shocks and poverty as poverty eradication has proven to be an extremely complex task for both governments and nongovernmental organizations (World Bank, 2004).

The main aim of this study is therefore to assess the significance of community gardens in coping with climate shocks as well as, focusing on the direct significance of the gardens on the participating farmers' livelihoods in Bikita District, Masvingo that is; food security status, income and poverty.

\subsection{The objectives of the research study}

- An in-depth assessment of the community gardens, the local people who are engaged in community gardening in Bikita District and their socio-economic status, knowledge, perceptions and attitude towards drought and other climate shocks;

- Successes, constraints and institutional support of community gardens in Bikita District and the overall significance of the activity as a drought and climate shock coping strategy; 
S. Afr. J. Agric. Ext.

Vol. 45, No. 1, 2017: $102-117$

DOI: http://dx.doi.org/10.17159/2413-3221/2017/v45n1a440
Muzawazi, Terblanché

\& Madakadze.

(Copyright)

- To analyse the needs and challenges of the community garden participants in Bikita to come up with an in-depth knowledge of how the activity can be supported and improved.

\section{LITERATURE REVIEW}

\subsection{Drought as a major climate shock}

Drought is a common occurrence in sub-Saharan Africa (SSA) in general, and particularly in Southern Africa. It has been defined as the condition of abnormally low rainfall, outside the normal expected parameters that would support productive activities. The frequency of droughts and below-normal rains seem to be increasing in line with climate change. Droughts significantly reduce food availability at both national and household level, as well as limiting rural employment possibilities. Poor smallholder farmers in Africa have had to face the reality of crop failure and acute food shortages. The largest food crises in Africa that required large-scale external food aid have been attributed fully or partially to extreme weather events. The impacts of droughts are contingent on the interaction of meteorological anomalies and these indirectly lead to increased environmental degradation, deforestation etc., which could be a factor in civil strife causations (Chikobvu, Chiputwa, Langyintuo, La Rovere, \& Mwangi, 2010).

In Zimbabwe, as in much of SSA, drought is frequent with devastating effects on household livelihoods. Drought, therefore, is a form of supply-side shock outside a country's control and has consequences on domestic economic variable. In Zimbabwe, the famines of 1974, 1982, 1992, 2002, and 2004 affected the lives and livelihoods of millions of rural households, and were mainly caused by droughts (Rukuni, 2006).

Risks associated with drought include: crop failure, lack of fodder for cattle, lack of water for cattle and irrigation, insufficient water for hygiene purposes, loss of income from agriculture, migration and associated impacts on families, increase in school drop-outs, increase in deforestation, loss of biodiversity and saline water intrusion. (Unganai \& Murwira, 2010).

\subsection{Conceptual framework}


S. Afr. J. Agric. Ext.

Vol. 45, No. 1, 2017: $102-117$

DOI: http://dx.doi.org/10.17159/2413-3221/2017/v45n1a440
Muzawazi, Terblanché

$\&$ Madakadze.

(Copyright)

Climate Signal

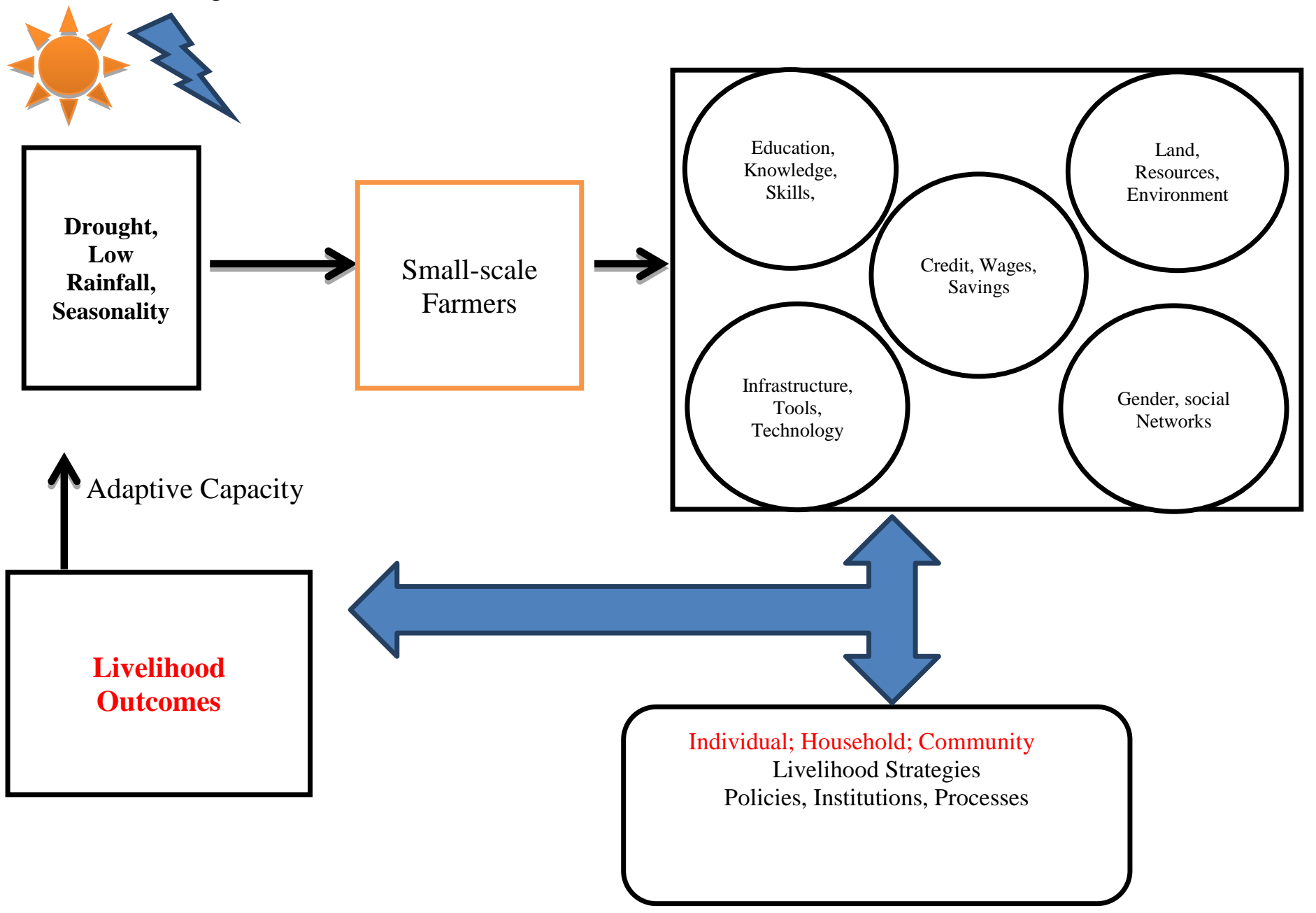

Figure 1: Conceptual framework.

Source of data (Fellmann, 2012) Vulnerability Frameworks - University Pablo de Olavide, Seville, Spain

The conceptual framework adapted in this study is built on the vulnerability framework. The framework was chosen because it enables the identification of factors that affect agricultural production for farmers especially in the rural areas.

Figure 1 attempts to show the vulnerability framework, which is a cycle of events on how the categories shown interact with each other in terms of how farmers can be affected by climate changes and how the vulnerability and adaptive capacity can be measured by their socioeconomic factors; their individual, household or community strategies (community gardens) in conjunction with institutional support and policies can assist to make their socio-economic factors better for them to adapt and handle stresses and shows thus having a more positive livelihood outcome.

\subsubsection{Climate signal}

The climate signal comprises long-term changes in average climate conditions, as well as changes in climate variability such as changes in the timing, intensity and duration of 
S. Afr. J. Agric. Ext.

Vol. 45, No. 1, 2017: $102-117$

DOI: http://dx.doi.org/10.17159/2413-3221/2017/v45n1a440
Muzawazi, Terblanché

\& Madakadze.

(Copyright)

precipitation and extreme weather events, like droughts and floods. The response of actors and systems depends on the characteristics of the climate stimulus, including the degree of exposure to the stress and the scale and magnitude of the event (Smithers \& Smit, 1997).

\subsubsection{Adaptive capacity}

Adaptive capacity is the ability (or potential) of a system to successfully adjust to climate change including climate variability and extremes (Pachauri \& Reisinger, 2007). Adaptive capacity comprises adjustments in both behaviour and in resources and technologies.

\subsubsection{Context of vulnerability}

The impact of climate change on the well-being of individuals, households, and communities and their ability to respond to those changes depends on the context in which climate change occurs (Adger, Dessai, Goulden, Hulme, Lorenzoni, Nelso; Naess, Wolf, \& Wreford, 2009). The context includes all the factors that determine an individual's, households, groups, or community's vulnerability to climate change.

This framework categorizes the main components of the vulnerability as biophysical characteristics, user characteristics, information and technology, and institutional arrangements. These components are interrelated, as indicated by the arrows connecting them.

Socio-economic factors are important for the adaptive capacity of a system; integral role of institutions, governance, and management in determining the ability to adapt to climate change. Some socio-economic determinants of adaptive capacity are generic, for example, education, income and health; others are specific to particular climate change impacts such as floods or droughts for example, institutions, knowledge and technology. The more adaptive capacity a system has, the greater is the likelihood that the system can adjust and thus is less vulnerable to climate change and variability (Fellmann, 2012).

\subsection{Potentials of community gardens}

Mass establishment of community gardens in Zimbabwe was done by Non-Governmental Organisations namely, Action Faim and CARE Zimbabwe in a bid to maintain sustainable rural livelihoods among the rural households. Communities have been upgrading communal gardens by selling the surplus production to obtain household income. Auret (1990) revealed that NGOs assist in establishing small irrigated vegetable gardens as they are a major component for the daily food consumption.

Community gardens have important resources with socio-economic reproduction roles for the communal people (Moyo \& Tevera, 2000). Some villagers have resorted to gardening while waiting for the rain season and they make profits using them for accessing inputs during the main season of farming (New Farmer, 2004).

Scoones (2010) postulated that gardens have benefited women through specialization and they obtained vegetables, groundnuts and Bambara nuts for the household food consumption. Communities have benefited from participation in those gardens where they derive their income. Community run schemes have performed better than government managed schemes because of their flexibility, lower cost of operation and participation of women (Rukuni, 
S. Afr. J. Agric. Ext.

Vol. 45, No. 1, 2017: $102-117$

DOI: http://dx.doi.org/10.17159/2413-3221/2017/v45n1a440
Muzawazi, Terblanché

\& Madakadze.

(Copyright)

2006). Community gardens in rural areas utilized wetlands as source of water to irrigate their crops and vegetables. These wetlands existed together with community gardens for many years and proved to be highly productive as they contribute to social and economic welfare of many rural families (Rukuni, 2006).

The gardens have also benefited households and chronically ill people with herbs and vegetables as they improve their nutrition throughout the year. These are also activities for women where income generation becomes easy for them. Medical plants found in these community gardens such as garlic and onions have role of treating HIV related symptoms, improving digestion and stimulating appetite (FAO, 2002). Gardens are for income generation and food producing activities. These are necessary for the contribution to food security and safety.

\subsection{Social benefits of community gardens}

Community gardens benefit the communities to build social networks through sharing gardening activities. According to Moyo \& Tevera (2000), family and kinship act as the distributive mechanisms as well as promoting interpersonal relations and social identity of individual members. This mainly happens in sharing gardens among the families who participate. Gardens have promoted intermarriages between the families and thereby building networks of kinship. Community gardens act as a survival strategy for the poor in many communities to share resources together to meet their daily basic needs and mutual obligations.

\subsection{Challenges faced in community gardens}

Community gardens face many challenges that limit their production and interaction between members. Lack of irrigation equipment undermined the ability of poor households to raise their agricultural incomes and made them even more vulnerable to frequent droughts. Power relations are an impediment to the success of gardens. These relations determine the controls of gardens. There are also illegitimate forms of transferring land or selling of land or expansion of plots which is common in gardens. This was because of usurpation of powers of traditional leaders to manage land and other natural resources lead to protest against rules (Moyo \& Tevera, 2000).

According to Middleton (2009), community gardens in rural areas face management challenges. Most of the participants in community gardens lack gardening skills. Community gardens attracted members which are political motivated and they tend to influence decision making. Middleton (2009) also noted that community gardens also face the challenge of water to irrigate fruits and vegetable during summer. Conflicts over control of land, competition between actors over use of scarce resources such as water because of population pressure are also common in community gardens.

The major key would be improving extension and support systems geared towards meeting the needs of small-scale farmers because they require different kinds of systems from commercial farms, which are generally prioritised by governments. This would mean that governments need to be proactive about engaging their subsistence and small-scale farmers in development projects and provide appropriate support for them. In recent years, there has been a great loss of extension officers in the region, due to HIV/AIDS. This is crippling a lot of small-scale farmers who need advice on how to deal with changing climate conditions 
S. Afr. J. Agric. Ext.

Vol. 45, No. 1, 2017: $102-117$

DOI: http://dx.doi.org/10.17159/2413-3221/2017/v45n1a440
Muzawazi, Terblanché

\& Madakadze.

(Copyright)

(Sosibo, 2011). There is a need to improve the extension and support system in the whole region.

\section{METHODOLOGY}

\subsection{Data collection}

Structured interviews were administered to a total of 130 randomly sampled community/ nutrition garden participants. The study also used semi-structured interviews which were administered to the donor agents involved in the gardening projects, that is, CARE and CARITAS International Organizations. A key informant interview was also administered to the district extension advisory officer for Bikita involved in the projects. In addition, the study made use of a focus group discussion which was held to capture farmers' perceptions of climate shocks and the general impact of community gardens.

\subsection{Data analysis}

Data collected from the household survey was entered, verified, coded and cleaned using the Microsoft Excel software package due to its ease of handling both string and coded variables. The coded data was exported into the Statistical Package for Social Sciences (SPSS 20.0) for Windows for descriptive analysis. The data was captured and analysed by the Department of Statistics at the University of Pretoria.

\section{RESULTS AND DISCUSSION}

\subsection{Farmer household characteristics and farmer's perception towards climate shocks and its effects}

The following was concluded on the farmer's socio-economic status and their knowledge and perceptions towards climate shocks:

- $86 \%$ of the community garden participants are female;

- There is an almost even distribution of community garden participants from all age categories of the youth (39\%); economically active (38\%) and the elderly (23\%) with the mean age being 47 years;

- Most participants have basic education (primary and secondary education);

- Respondents are not formally employed but rather self-employed farmers with their main source of income coming from farming and gardening activities;

- Farmers expressed some significant ignorance to the knowledge and existence of climate shocks, but they did agree to the effects that drought has brought to their products in the past decade. Chi-square test also revealed no significant association between age groups and knowledge of climate shocks;

- There are no neither weather stations in the area, nor any weather station gadgets available to assist farmers in predicting weather patterns and prepare for farming seasons;

- The Chi-square test was used to determine age group association and responses given with regards to climate shocks adaptation projects helping to cope with drought and climate change and results showed that the economically active age group did not respond positively to the impact of climate shocks adaptation projects. 
S. Afr. J. Agric. Ext.

Vol. 45, No. 1, 2017: $102-117$

DOI: http://dx.doi.org/10.17159/2413-3221/2017/v45n1a440

\subsection{The overall significance of community gardens in Bikita district}

In Zimbabwe, while land is jointly owned in community gardens, each farmer has his/her own allocation within a large garden area. The size of holding per farmer is determined by the number of beneficiaries in the households, land size available, water availability, farming equipment and ability to utilize the land fully. Each household has an average total area of at least 0.06 hectares. Infrastructure is owned collectively. The community gardens manage their activities through the establishment of management committees. The interviewed farmers in Bikita District have been practising community gardening from between three weeks to 25 years.

Figure 2 shows the various reasons why farmers have adopted community gardening as a coping mechanism for drought and climate shocks.

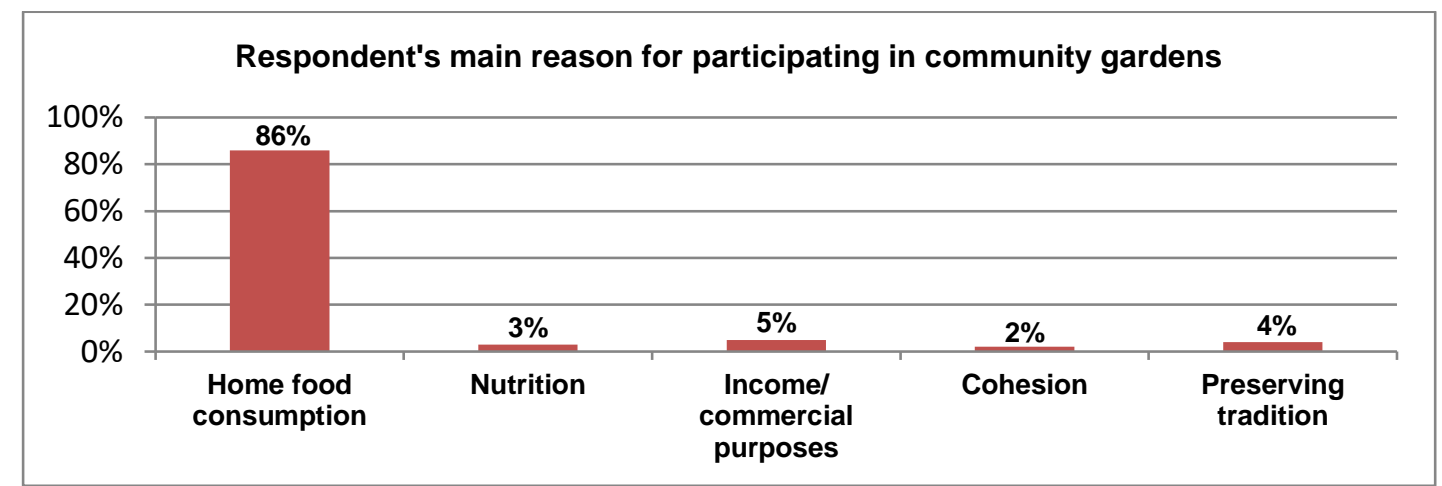

Figure 2: Main reason for participating in community gardens

As seen in Figure 2 above $86 \%$ of the members of community gardens pointed out that they entered community gardening to produce food for home consumption. Similarly, income generation has also appeared to be a significant driving factor that motivates people to join community gardens. Normally, income is generated when they begin to sell the surplus of the food produced.

According to the study, farmers in the community gardens engage mostly in horticulture vegetable production and crop production. Vegetables planted in the community gardens mainly include; rape (kale), covo, cabbages, tomatoes, onions, carrots and chillies. Tomatoes, covo, onions and rape are more popular than the rest because the seeds are more accessible. Crops grown include round nuts; groundnuts; maize and sugar beans.

Complete sale of crops and vegetables is not always guaranteed and because of the low prices charged by farmers, there is little or no income after sale. Findings report that a small plate consisting of 10 tomatoes will sell for only US\$0.50. A bundle of rape vegetable sells for US\$0.50 each.

Results also showed that:

- $53 \%$ of the respondents do not get any income from their community gardening. The produce is mainly used for household food consumption;

- $49 \%$ of the farmers earning an income use the money to purchase basic food such as milk, bread, sugar and cooking oil;

- $35 \%$ save their income and eventually use it to pay school fees and cater for children's necessities like clothing and school item requirements; Results from the 
S. Afr. J. Agric. Ext.

Vol. 45, No. 1, 2017: $102-117$

DOI: http://dx.doi.org/10.17159/2413-3221/2017/v45n1a440
Muzawazi, Terblanché

$\&$ Madakadze.

(Copyright)

Chi-square test $(\mathrm{p}=0.295)$ showed that there was no significant association between age group and response to using income for school fees and children's necessities;

- $25 \%$ of the farmers plough the money back into the business. Chi-square test $(\mathrm{p}=0.310)$ result also showed no significant association between age group and response to ploughing income back into the business; and

- $25 \%$ use their income to purchase more farm inputs and farming equipment for use in the community gardens.

\subsection{Social benefits}

Social benefits of community gardens were also considered as an important factor affecting farmers' adoption of the gardening activities. Focus group discussions were mainly used as a platform to raise points on some of the social benefits associated with community gardens. Farmers learn different techniques, training and farming skills from Government and NonGovernmental Organizations which enhances their knowledge as farmers and as individuals.

Members easily assist each other in caring for crop and vegetables. Individual unique skills and knowledge are shared amongst the members of the community. Community members also share farm implements and equipment.

\subsection{Economic benefits}

Nutritious food was the most important benefit mentioned by the community garden members. The gardens provide a variety of crops and vegetables which are used for household consumption and farmers have a mixed choice from the wide substitute that crops bring, and provide the same nutrients that meat provides. Secondly, they identified that growing their own fresh, healthy and nutritious vegetables helped them achieve food security; they stated that being able to produce for their own food helped them reduce their vulnerability to hunger.

Many of the members, most of them women, are happy to be members of community gardens because they feel the gardens have become a source of formal employment for them. The respondents mentioned that they feel satisfied by the fact that they now wake up and go to work. Community gardens have also enabled the women to take up the role of providing for the household as well as contributing financially.

\subsection{Environmental benefits}

Farmers noted how the community gardens have helped regain their soil's survival. Soil and land had been lying idle for many years due to little or no agricultural production. Now soil can be kept fertile due to the different types of crops and vegetables planted in the community garden. Farmers also mentioned that they practise crop rotation which is an effective way of maintaining soil fertility.

\subsection{Institutional support of community gardens and farmers' constraints to production}

Several farmers argued that advice from agricultural extension officers and NGOs has been of paramount significance to them in adapting to climate change and variability and to farmers' lives. Networks have been created with stakeholders to assist with adaptation and mitigation strategies. One example is the new cropping systems introduced by NGO's such as Action Faim, CARITAS and CARE International in Bikita District and other surrounding districts. 
S. Afr. J. Agric. Ext.

Vol. 45, No. 1, 2017: $102-117$

DOI: http://dx.doi.org/10.17159/2413-3221/2017/v45n1a440
Muzawazi, Terblanché

\& Madakadze.

(Copyright)

\subsection{Extension services for community farmers in Bikita district}

Zimbabwe's agricultural extension service, AGRITEX, was the pride of Africa in the 1980s, before the ravages of structural adjustment hit in the 1990s. There were extension workers throughout the countryside, and a network of subject matter specialists, most highly experienced and qualified. The quality of the training and advice offered was unparalleled anywhere on the continent, and for a time the service was well resourced with extension workers reasonably paid and with transport, therefore, able to easily move around (Scoones, 2014).

Today the extension service is a sorry reflection of past glories. Many qualified staff left or passed away, posts are unfilled, and the transport capacity is virtually non-existent and the ability to offer up-to-date advice severely hampered by the parallel decimation of government research services. Most farmers rely on private input suppliers, agro-dealers and their neighbours for advice. Of course, there are extension workers in the field, and they are usually extraordinarily committed and informed, despite the poor conditions of their posts. In the rural areas many get additional incentives from NGO programmes, often diverting their work to projects like conservation agriculture or community gardening (Scoones, 2014).

Within AGRITEX, there is little information on how many farmers it is actually reaching and servicing to date. The extension agency offers a blanket public good service, which farmers are expected to use. Large-scale commercial farmers perceive AGRITEX as generally not competent to provide advisory services to their subsector. The majority of these farmers rely on support services from private agro-based companies (Hanyani-Mlambo, 2002).

Table 1 shows the extension/ advisory service providers who are actively involved in assisting community farmers in Bikita district.

Table 1: Extension/ advisory service providers in Bikita District

\begin{tabular}{|c|c|c|}
\hline Extension service provider & \begin{tabular}{|ll}
$\begin{array}{l}\text { Number } \\
\text { respondents }\end{array}$ & of \\
\end{tabular} & Percentage \\
\hline No extension services & 3 & 2 \\
\hline Government & 20 & 15 \\
\hline NGOs & 2 & 2 \\
\hline Private Organizations & 4 & 3 \\
\hline Educational Institutions & 7 & 6 \\
\hline Agricultural Associations & 94 & 72 \\
\hline Total & 130 & 100 \\
\hline
\end{tabular}

As illustrated in Table 1, 72\% of the respondents said they received extension services form agricultural associations in the district while $15 \%$ mentioned that they received their extension services from the government.

According to (Dhewa, 2011), although they do not receive much recognition, agricultural associations like agro-dealers are major economic drivers in rural areas of Zimbabwe. One of the most successful associations mentioned by the farmers is Masvingo Agro-Dealer Association (MADA), which comprises business membership organisations from Masvingo 
S. Afr. J. Agric. Ext.

Vol. 45, No. 1, 2017: $102-117$

DOI: http://dx.doi.org/10.17159/2413-3221/2017/v45n1a440
Muzawazi, Terblanché

\& Madakadze.

(Copyright)

province's seven districts: Bikita, Zaka, Chivi, Masvingo, Gutu, Mwenezi and Chiredzi. Masvingo Agro-Dealers Association (MADA) is demonstrating the capacity and potential of agro-dealers in availing inputs and business knowledge to smallholder farmers. Most members are agro-dealers, general dealers, flea market traders and rural artisans (carpenters and welders). Masvingo Agro-Dealers Association came into existence in 2005 as an offshoot from Care Zimbabwe's Agribusiness Entrepreneur Network \& Training (AGENT) programme which aimed to provide smallholder farmers in remote areas with agriculture inputs at affordable prices by establishing a network of agro-input dealers (Dhewa, 2011). Inefficiencies in agriculture value chains had excluded smallholder farmers from local trade. The AGENT programme identified and facilitated market based solutions to handicaps that were preventing farmers from obtaining inputs. Agro-dealer networks were expanded through training rural traders and linking them with private sector suppliers and micro finance institutions to improve affordability and volumes of inputs for smallholder farmers. Some of the major skills agro-dealers provide include merchandising, marketing, record keeping, input handling, conflict management, leadership, cattle fattening, value addition as well as lobbying and advocacy.

Demonstrations through field days are used by agro-dealers to show how their inputs work (Dhewa, 2011). Table 2 indicates how farmers rated the quality of extension services they receive from extension bodies.

A Chi-Square test ( $\mathrm{p}=0.762$ ) was conducted to show the relationship between age groups and how they responded to rating the extension services in their area. Results showed that there was no significant association between age group and how they rated extension services.

Table 2: Quality of extension services rated by the respondents in the community gardens

\begin{tabular}{|c|c|c|}
\hline & $\begin{array}{|ll|}\begin{array}{l}\text { Number } \\
\text { respondents }\end{array} & \text { of } \\
\end{array}$ & Percentage \\
\hline Poor & 8 & 6 \\
\hline Average & 71 & 55 \\
\hline Good & 17 & 13 \\
\hline Excellent & 34 & 26 \\
\hline Total & 130 & 100 \\
\hline
\end{tabular}

Table 2 shows that, 55\% of the respondents rated extension services received in their area as average while $26 \%$ rated extension services as excellent and $13 \%$ rated the quality of extension as good.

\subsection{Quality of support services}

Figure 3 indicates the quality of support services as perceived by the participants of the community gardens. 


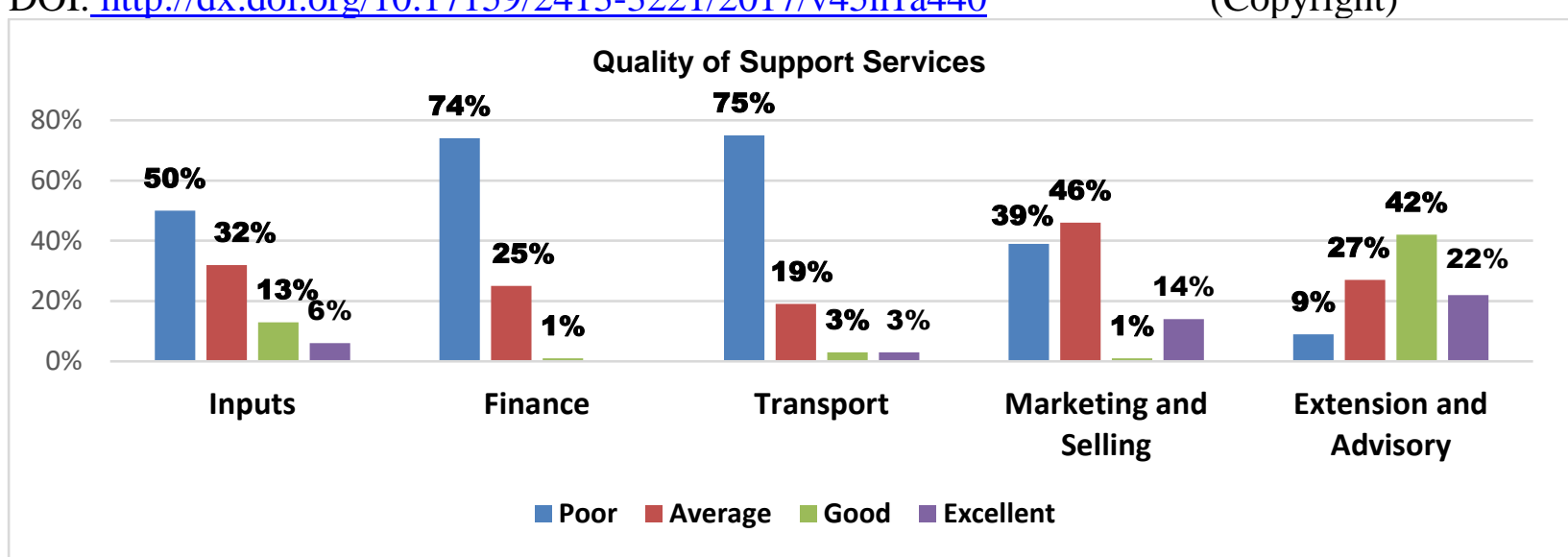

Figure 3: Quality of support services received

Farmers were asked to rate the quality of services they receive from service providers as shown in Figure 3. The greater percentage of farmers rated inputs $(50 \%)$, finance $(74 \%)$ and transport $(75 \%)$ as poor. Marketing and selling $(46 \%)$ were rated average and extension and advisory services $(42 \%)$ were rated as good, $22 \%$ rated them as excellent. Farmers have a good relationship with the extension officers in their wards because they do their best to attend to their needs.

\subsection{Major constraints indicated by farmers in community gardens}

This section deals specifically with constraints that were identified by community garden members as hindering the progress that would have been realised by farmers. Being a member of a community garden is not easy, one is always faced with problems that are within one's control, and some even extend beyond the individual's control. Sadly, one problem is that often community gardens blossom when nobody is keeping an eye on the livestock. That poses a great risk of crops being tarnished or destroyed by livestock.

Some of the community garden members are older people who find it difficult to complete the garden activities. They find it difficult to walk from their households to the garden and fetching water is a problem. Community gardens also face management challenges. Gardens are expensive to set up and maintain, they often suffer vandalism, internal disagreements can pause a negative impact on development and too much bureaucracy in decision making.

\subsection{Water supply}

Despite the various water sources and methods of water storage, most of the farmers have stressed the fact that there in insufficient water to last the entire production cycle. According to the data, the river sometimes dries up or is very low, while demand is high, making it nearly impossible to continue with agricultural activities. Extreme circumstances of dry weather sometimes even force them to stop the gardening completely as vegetables require a constant supply of water.

Figure 4 shows farmers' responses towards the water sufficiency for gardening activities. 


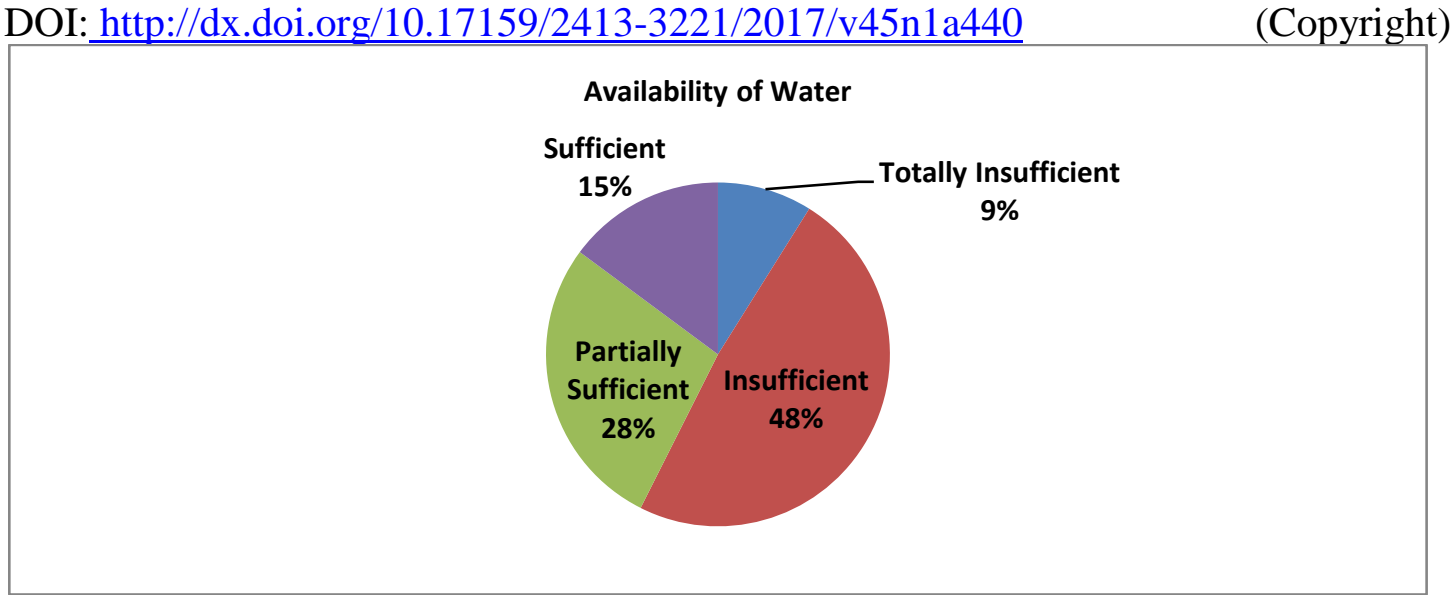

Figure 4: Water sufficiency as perceived by respondents

Water is insufficient for gardening purposes, as indicated by $48 \%$ of the respondents. According to the study, the two major sources of water are the river and dam and they both rely on rainfall for water supply. Due to the high temperatures and the dry spell, the river is almost always dry as demand for water is high, not only for gardening purposes but also for domestic purposes by the locals. Water is partially sufficient for $28 \%$ of the respondents, while only $15 \%$ noted that water is sufficient. This is because they reside near the river and have easy access to water at any time. Gardening, as mentioned by the respondents, is an activity that requires water daily, as most of the vegetables and crops require water daily for them to thrive. The result is that the demand for water increases, while the supply stays constant.

Besides water, farmers also highlighted several other constraints affecting their day-to-day activities at the community gardens. Farmers were asked to rank the 3 main shortcomings that they face (in the order from $1=$ most important; $2=$ second most important to $3=$ most unimportant) in the community garden production process.

The results showed that:

- $55 \%$ of the farmer's ranked long distance to gardens as a most important constraint to their production and $25 \%$ ranked it as second most important.

- $58 \%$ of the respondents ranked no fencing or protection as the most important constraint.

- $22 \%$ of the farmers ranked birds and predators as a most important shortcoming and $62 \%$ ranked them as second most important shortcoming.

- A major constraint mentioned by the farmers during data collection activities was high the supply of crops and vegetables but low demand available. With many members of the community participating in community gardens, there is a high supply of the same types of crops and vegetables. A lack of proper markets and selling points, farmers are forced to sell their produce on a door to door basis in the community or use the goods for exchange of services and labour.

The study also ranked the most serious factors that are negatively affecting the farmers' production. These include; limited access to water (68\%), poor access to inputs (58\%), limited access to finance (55\%), lack of farm equipment (49\%), limited access to climate information (44\%) and, poor markets (38\%). Again, it is seen that, limited access to water is the most serious production constraint in the area. 
S. Afr. J. Agric. Ext.

Vol. 45, No. 1, 2017: $102-117$

DOI: http://dx.doi.org/10.17159/2413-3221/2017/v45n1a440

\subsection{The desired frequency of support services by farmers}

After discussing and concluding the constraints that the farmers are facing during production, the respondents were asked how frequently they would desire support services for their agricultural activities to thrive.

Figure 5 illustrates the various responses that community garden participants gave.

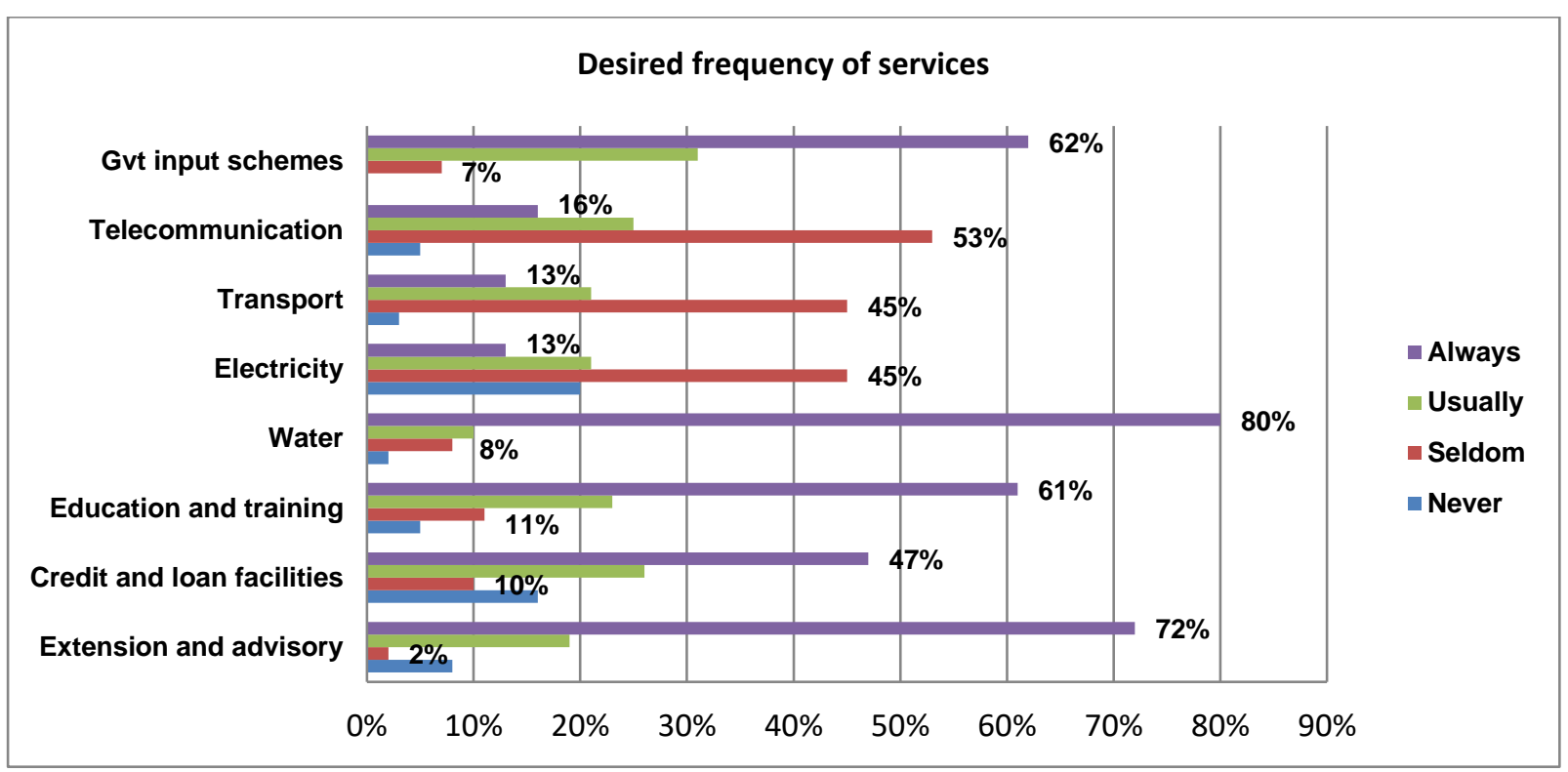

Figure 5: Desired frequency of support services according to respondents

According to Figure 5, water had the highest number of responses with $80 \%$ of the respondents saying they always require access to water as it is the major cause of concern because of its insufficiency. Extension and advisory services were indicated as something constantly desired by $72 \%$ of the respondents. Farmers have faith in their extension workers because they can mediate for them and carry over their grievances and needs to the government. Extension workers have access to telecommunication and information on market changes, climate change and have access to research and development which they can relay back to the farmers in their wards. The survey indicated that the farmers require an increase in the number of visits by extension workers to 2-3 times a month for them to always be up to date with the market trends, commodity prices and general agricultural information in the province.

Always having access to government input schemes is preferred by $62 \%$ of the farmers. Respondents, during the focus group discussions, argued that, the government inputs schemes usually target the established farmers and those farmers that are easily accessible to government workers, namely, those who are situated near the major routes or around business centres. They neglect those farmers who are deep inside the rural areas and do not have good access roads. Credit and loan facilities will always be required by $47 \%$ of the respondents. The participants mentioned that these services are usually rendered according to farmers' status in the society and to the farmers who can access the services themselves. According to the survey, $61 \%$ of the respondents said they always require education and training as a source of information to assist with efficiency and effectivity of production in their community gardens. 
S. Afr. J. Agric. Ext.

Vol. 45, No. 1, 2017: $102-117$

DOI: http://dx.doi.org/10.17159/2413-3221/2017/v45n1a440
Muzawazi, Terblanché

\& Madakadze.

(Copyright)

In addition, $53 \%$ of the respondents mentioned they seldom require telecommunication; $45 \%$ seldom require transport and $45 \%$ seldom require electricity. The major reasons mentioned for seldom requirement of these services was mainly because that the respondents cannot afford them. However, $13 \%$ said they do always require electricity. A total of $44 \%$ said they would require transport on a regular basis, while $33 \%$ highlighted that they would seldom require transport due to the fact that, even if made available, they would rarely be able to afford it.

\section{CONCLUSIONS AND RECOMMENDATIONS}

The farmers reiterated that gardening is an activity that has great potential for sustainable growth and food security for the locals living in rural areas but it requires a lot more attention. Even though many activities are taking place in Bikita, with regards to adaptation and coping with climate shocks, more needs to be done in terms of implementing the programmes and coming up with ways of assisting the participants to start up and progress in terms of production. This study emphasises that community gardens have a lot of potential and can improve if the following strategies are adopted:

- Providing more avenues/sources of funding, other than the already struggling government, to improve on community garden production. Government, NGO's and private sector must work together (a coordinated approach) to establish means of finances to run such programmes. Without available financial resources, community gardens cannot reach their full potential.

- Improvement on, and/or additional water sources such as the construction of water reservoirs, dams, boreholes and irrigation equipment should be made available, especially near community gardens to provide sufficient water.

- It is also recommended that adult education programmes be strengthened in the rural areas to reduce illiteracy among farmers. Extension agents in the area should incorporate climate change information in their extension messages while government should intensify efforts in integrated rural development. Development can be in the form of infrastructural facilities like better roads and telecommunication facilities to improve communication amongst the agricultural stakeholders. There is also a need for a structured coordinated extension programme to address farmer's needs effectively and efficiently.

- More support should be given to agricultural associations like the agro-dealers associations, as they play a vital role in supporting small holder farmers in the rural areas. Knowledge and dissemination of the importance of joining associations should be spread to the farmers involved in community gardens. Introduction of agro-dealer associations will support and encourage group production rather than individual farming in the gardens. Associations will help farmers to produce goods in bulk and link them to wholesalers and retailers. Subscription fees and monthly membership fees can go a long way in maintaining the welfare of the gardens and transport of goods can be made possible by such funds.

\section{REFERENCES}

ADGER, WN., DESSAI, M., GOULDEN, M., HULME, S., LORENZONI, DR., NELSO, C., NAESS, LO., WOLF, J., \& WREFORD, A., 2009. Are there social limits to adaptation to climate change? Climate Change. 93:335-354.

AURET, D., 1990. A decade of development in Zimbabwe 1980-1990, Gweru: Mambo Press. 
S. Afr. J. Agric. Ext.

Vol. 45, No. 1, 2017: $102-117$

DOI: http://dx.doi.org/10.17159/2413-3221/2017/v45n1a440
Muzawazi, Terblanché

\& Madakadze.

(Copyright)

CHIKOBVU, S., CHIPUTWA, B., LANGYINTUO, A., LA ROVERE, R. \& MWANGI, W, 2010. Characterization of maize producing households in Masvingo and Bikita Districts in Zimbabwe, Nairobi: International Maize and Wheat Improvement Centre (CIMMYT).

FAO, 2002. The state of food aid agriculture in Africa, Rome: FAO.

FELLMANN, T., 2012. The assessment of climate change related vulnerability in the agricultural sector: Reviewing conceptual frameworks, Seville: University Pablo de Olavide Department of Economics.

HANYANI-MLAMBO, B., 2002. Strengthening the pluralistic agricultural extension sysytem: A Zimbabwean case study, Rome: Economic and Social Development Department.

KAHINDA, M., ROCKSTROM, J.A.E., TAIGBENU, A., DIMES, J., 2007. Rainwater harvesting to enhance water productivity of rainfed agriculture in semi-arid Zimbabwe., s.l.: Physics and Chemistry of the Earth.

MIDDLETON, J., 2009. Community gardening, Colombia: University of Missouri.

MOYO, S. \& TEVERA, D., 2000. Environmental security in Southern Africa, Harare: SAPES Trust.

MUTEKWA, V., 2009. Climate change impacts and adaptation in the agricultural sector: The case of smallholder farmers in Zimbabwe. JSDA. 2:237-256.

NEW FARMER, 2004. Zimbabwe's leading voice of agriculture, Harare: Ministry of Agriculture.

PACHAURI, R. \& REISINGER, A., 2007. Fourth assessment report of the intergovernmental panel on climate change, Geneva: IPPC.

RUKUNI, M., 2006. Zimbabwe's agricultural revolution revisited, Harare: University of Zimbabwe Publications.

SCOONES, I., 1998. Hazards and opportunities. Farming livelihoods in dryland Africa: Lessons from Zimbabwe. Sustainable Rural Livelihood a Framework for Analysis, Issue 72.

SCOONES, I., 2010. African Issues: Zimbabwe's land reform: myths and realities, Harare: Weaver Press.

SCOONES, I., 2014. Rethinking agricultural extension, Harare: Zimbabwe Land.

SLATER, R., PESKETT, L., LUDI, E., BROWN, D., 2007. Climate change, agricultural policy and poverty reduction - how much do we know, s.l.: Natural Resource Perspectives.

SMITHERS, J. \& SMIT, B., 1997. Human adaptation to climatic variability and change. Global Environmental Change. 3:129-146.

SOSIBO, K., 2011. Women at the mercy of climate change.

UNGANAI, L. \& MURWIRA, A., 2010. Challenges and opportunities for climate change adaptation among smallholder farmers in Southeast Zimbabwe. Ceara, Department of Geography and Environmental Science, University of Zimbabwe.

WANI, S., ROCKSTROM, J. \& OWEIS, T., 2009. Rainfed Agriculture: Unlocking the potential. Comprehensive Assessment of Water Management in Agriculture Series. 7:9.

WORLD BANK, 2004. Reaching the poor a renewal strategy for rural development, Washington DC: World Bank. 